\title{
SHOX Deficiency in Argentinean Cohort: Long-Term Auxological Follow-Up and a Family's New Mutation
}

\author{
Mariana del Pino ${ }^{10}$ Miriam Aza-Carmona ${ }^{2,3,4}$ David Medino-Martín ${ }^{2}$ Abel Gomez ${ }^{5}$ \\ Karen E. Heath ${ }^{2,3,4}$ Virginia Fano ${ }^{1}$ María Gabriela Obregon ${ }^{5}$
}

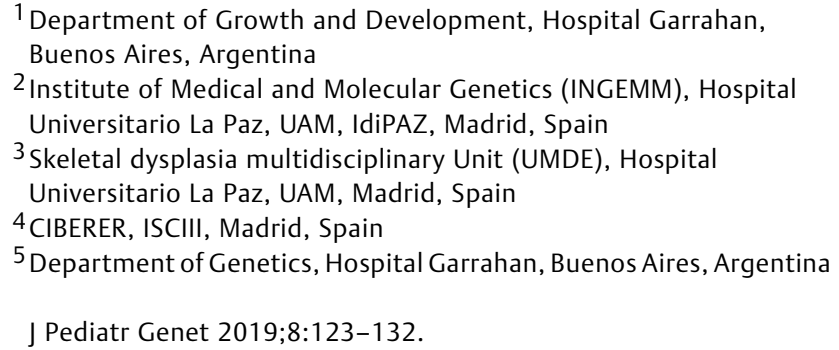

\begin{abstract}
Address for correspondence Mariana del Pino, MD, Department of Growth and Development, Hospital Garrahan, Combate de los Pozos 1881 (1245), Buenos Aires, Argentina

(e-mail: mdelpino@intramed.net; mdelpino@garrahan.gov.ar).
\end{abstract}

\begin{abstract}
A cohort study on the growth of 19 Argentinean children, aged 0 to 18 years, and 11 of their first-degree relatives with alterations in the SHOX gene or its regulatory regions is reported. Children are born shorter and experience a growth delay during childhood with a stunted pubertal growth spurt. Body disproportion, with a sitting height/height ratio above +2 standard deviation score (SDS), was already present as early as 2 years old. Hand length was normal. Shortening of the radius, with a length below -1.9 SDS, was the earliest and most frequent radiological sign detected as early as 45 days old.

Keywords

- SHOX gene

- Leri-Weill dyschondrosteosis

- body disproportion We found a previously unreported mutation in a family with a highly variable phenotype, the boy had a severe phenotype with a milder presentation in other affected members of the family. We conclude that body disproportion and a shorter radius length on X-ray are useful tools for selecting children to undergo SHOX molecular studies.
\end{abstract}

\section{Introduction}

SHOX (short stature homeobox-containing gene) haploinsufficiency may result in the skeletal dysplasia, Leri-Weill dyschondrosteosis (LWD), ${ }^{1,2}$ characterized by disproportionate short stature due to mesomelic limb shortening and Madelung deformity (the bowing and shortening of the radius, distal dislocation of the ulna, and a pyramidal configuration of the carpal bones). Other physical features may include a higharched palate, cubitus valgus, short fourth metacarpal, micrognathia, and muscular hypertrophy. ${ }^{3,4}$

(D) Mariana del Pino's ORCID is https://orcid.org/0000-0001-60957080.

received

November 23, 2018

accepted

April 16, 2019

published online

May 28, 2019

The penetrance of SHOX haploinsufficiency is high, but its clinical expression is variable. The clinical and radiological features become more pronounced with increasing age and are often more severe in females. ${ }^{5-8}$ Short stature and features of LWD in Turner syndrome are secondary to SHOX haploinsufficiency and there are some studies describing longitudinal growth in Turner syndrome. ${ }^{9,10}$ However, there is limited information regarding longitudinal growth of children with isolated LWD. ${ }^{4-10}$

LWD patients have been reported to have a mildly reduced birth length, which, paired with growth retardation during infancy and childhood, results in short stature. ${ }^{11}$ The pubertal growth spurt also seems to be stunted, resulting in an additional height deficit during adolescence. ${ }^{11}$

Here, we report the results of an observational and retrospective cohort study on the longitudinal growth of 19

Copyright @ 2019 by Georg Thieme Verlag KG, Stuttgart . New York
DOI https://doi.org/ 10.1055/s-0039-1691788. ISSN 2146-4596. 
Argentinean children with molecularly confirmed alterations in SHOX or its regulatory regions. Data include anthropometric and X-ray follow-up. We also report this data in 11 first-degree relatives.

\section{Patients and Methods}

\section{Patients}

All children, aged 0 to 18 years, included in this study, were patients between 1992 and 2017 at the multidisciplinary growth clinic in the Department of Growth and Development in the Hospital Garrahan, Buenos Aires, Argentina, the main tertiary public pediatric hospital in Argentina, where children with skeletal dysplasias are referred to.

Testing for alterations in SHOX or its regulatory regions was performed in children if they fulfilled two or more of the following criteria:

(1) Short stature, defined as height $<2$ standard deviation score (SDS) below the mean for age and sex for Argentinean references ${ }^{12}$ or $<2$ SDS for target height without any other identified etiology to explain it and/or a family history of short stature.

(2) Arm span $<2$ SDS below the mean for age and sex using Turkish references. ${ }^{13}$

(3) Body disproportion, defined as: (i) Sitting height/ height ratio $(\mathrm{SH} / \mathrm{H})>2$ SDS for age and sex compared with the Argentinean references, ${ }^{14}$ and/or (ii) extremities-trunk ratio (calculated by the sum of the arm span and subischial leg length divided by the sitting height) for height ratio $<1$ SDS below the mean. ${ }^{7}$

(4) Clinical signs of mesomelic shortening of the forearms, lower limbs, or Madelung deformity.

Exclusion criteria for this study included: (1) presence of any other chronic disease or comorbidities that could affect growth, and (2) patients who had received growth hormone treatment. Group 1 consisted of 19 children who complied with these clinical criteria and were found to have an alteration of SHOX or its regulatory regions. Group 2 consisted of the cross-sectional data from 11 adults, who were first-degree relatives of the selected children and who had the familial SHOX alteration.

\section{Methods}

All patients, parents, or guardians gave their written informed consent to participate in the study. The following information was collected for each patient:

Anthropometric measurements: Birth weight, birth length, and head circumference were obtained from information registered on perinatal forms provided by the parents.

Height, weight, head circumference, arm span, total hand length, and sitting height were measured during each clinical follow-up. All patient measurements were initially taken and followed up by the same trained observer during the entire study period (1992-2017), with standardized anthropometric techniques. ${ }^{15}$

Height, sitting height, and hand length were measured with Harpenden instruments; head circumference was mea- sured with a nonstretchable, plastic tape measure; arm span with a rule with $1 \mathrm{~mm}$ divisions; and weight with bean balance scales. Mean intraobserver technical error of measurement for height, weight, head circumference, and arm span were $0.10 \mathrm{~cm}, 0.10 \mathrm{~kg}, 0.10 \mathrm{~cm}$, and $0.66 \mathrm{~cm}$, respectively. Weight/height ${ }^{2}$ (body mass index), $\mathrm{SH} / \mathrm{H}$, extremitiestrunk, and head circumference/height $(\mathrm{HC} / \mathrm{H})$ ratios were calculated as previously described. ${ }^{7,14,16}$

Individual growth curves of height, $\mathrm{SH} / \mathrm{H}$, and $\mathrm{HC} / \mathrm{H}$ for age were plotted on national references graphs. ${ }^{12,14,16}$

Height, $\mathrm{SH} / \mathrm{H}$, and $\mathrm{HC} / \mathrm{H}$ for age and sex SDS scores were estimated from local data references. ${ }^{12,14,16}$

Arm span and hand length for age was transformed into SDS based on Turkish and U.S. references. respectively. ${ }^{13,17}$

Pubertal development: Genital development in boys $(G)$ was scored visually on the Tanner scale and by palpation of testicular volume by Prader orchidometer. Testicular volume $>3 \mathrm{~mL}$ was considered pubertal onset. ${ }^{18,19}$ Breast development in girls (B) was scored both visually and by palpation to detect the budding in stage 2 and to discriminate mammary gland tissue from fat tissue. ${ }^{18,20}$

$X$-rays: Bilateral anterior-posterior hand and forearm Xrays were analyzed according to X-ray signs of wrist dysplasia described by Binder et al. ${ }^{7}$

Measurements of the maximum length of the radius were made to the nearest $0.1 \mathrm{~cm}$, along its longitudinal axis. The majority of the measurements were digitally performed but a few were manually measured using a millimeter ruler, again to the nearest $0.1 \mathrm{~cm}$. Radius length SDS scores, for age and sex, were estimated based on Gindhart's references. ${ }^{21}$

Molecular analysis: Genetic analysis included the analysis of deletions or duplications of SHOX and its regulatory regions using the MLPA P018G1 kit according to the manufacturer's instructions (MRC Holland, The Netherlands). Subsequently, negative cases were analyzed for mutations within exons 2 to 6 of SHOXa (NM_000451.3) using a combination of high-resolution melting and DNA sequencing. Analysis of the coding exons and intron:exon boundaries of the SHOX modifier, CYP26C1 (NM_183374.2), was also performed in all individuals from both groups by Sanger sequencing. Primers and PCR conditions are shown in -Table 1.

Statistical analysis: Results were expressed as mean + standard deviation (SD). SDS was determined using the LMS method $^{22,23}$ with the LMSgrowth Program. ${ }^{24}$

\section{Results}

A total of 19 children from 15 families with SHOX deficiency were studied in addition to first-degree relatives in an observation and retrospective study of their longitudinal growth.

Molecular results: Fourteen of 15 families had pseudoautosomal region 1 (PAR1) deletions, 13 including SHOX and 1 including only the four downstream regulatory regions (both father and his children, 2 boys) (-Table 2). One family had a previously undescribed missense variant in 
Table 1 List of the primer sequences, amplicon size, and PCR conditions for the amplification of CYP261 (NM_183374.2)

\begin{tabular}{|c|c|c|c|c|}
\hline Ex & Oligonucleotide (F 5'-3') & Oligonucleotide (R 5'-3') & Size (bp) & $\operatorname{Temp}\left({ }^{\circ} \mathrm{C}\right)$ \\
\hline 1 & TTTTGCGGACGGAACAGG & CATGGGCATTGAGACTGAGGAG & 392 & $56^{\mathrm{a}}$ \\
\hline 2 & GCTGGAAGGTCTGGGTCA & CGGGTTCACAGTGTATCCAAC & 400 & $57^{a}$ \\
\hline 3 & GGAACTGGCCTTCTGGCTAC & GTGCGCCGAGGGCGT & 446 & $62^{a}$ \\
\hline 4 & CACAAGGATGTTGGCAGAGC & AAAGTGGGGCCACACAAGAT & 365 & 60 \\
\hline 5 & GGCGACTCCACCGCCCGAGACT & GGCCATGGGCTGGCACGGCGCACTT & 500 & $65^{a}$ \\
\hline 6 & TCCTCCTGGTTTTCGGAAGC & CTACAATGGGGAGCGGCAGA & 569 & $\mathrm{TD}^{\mathrm{a}}$ \\
\hline
\end{tabular}

Abbreviations: bp, base pair; DMSO, dimethyl sulfoxide; PCR, polymerase chain reaction; TD, touchdown.

a5\% DMSO added to PCR; PCR starting at an annealing temperature of $65^{\circ} \mathrm{C}$ for 16 cycles, decreasing $0.5^{\circ} \mathrm{C}$ each cycle and then $20 \mathrm{cycles}$ at $57^{\circ} \mathrm{C}$.

Table 2 List of SHOX alterations identified in 15 families

\begin{tabular}{|l|l|l|l|l|}
\hline $\begin{array}{l}\text { Family } \\
\text { (GARR) }\end{array}$ & $\begin{array}{l}\text { MLPA P018 } \\
\text { version }\end{array}$ & Molecular results & $\begin{array}{l}\text { SHOX transcription regions } \\
\text { included in deletion }\end{array}$ & $\begin{array}{l}\text { SHOX alteration } \\
\text { classification }\end{array}$ \\
\hline 1 & F1 & Del L10292 - L19677 & CNE-5, -3, -2, SHOX, CNE4, 5, ECR1, CNE9 & SHOX deletion \\
\hline 2 & F1 & Del L20651 - L15507 & SHOX, CNE4, 5 & SHOX deletion \\
\hline 3 & F1 & Del L20651 - L00712 & $\begin{array}{l}\text { CNE-5, -3, -2, SHOX, CNE4, 5, ECR1, } \\
\text { CNE9 (Extends to ASMT) }\end{array}$ & SHOX deletion \\
\hline 4 & F1 & Del L20651 - L20177 & SHOX, CNE4, 5 & SHOX deletion \\
\hline 5 & F1 & Del L10292 - L19679 & CNE-5, -3, -2, SHOX, CNE4, 5, ECR1, CNE9. & SHOX deletion \\
\hline 6 & G1 & Del L24430 - L24247 & CNE-3, CNE-2, SHOX & SHOX deletion \\
\hline 7 & G1 & Del L25088 - L24250 & CNE-2, SHOX, CNE4, 5, ECR1, CNE9 & SHOX deletion \\
\hline 8 & G1 & $\begin{array}{l}\text { Exon 2 variant: } \\
\text { C.243A > T (p.Lys81Asn) }\end{array}$ & - & SHOX mutation \\
\hline 9 & G1 & Del L10292 - L24245 & CNE-5, -3, -2, SHOX, CNE4, 5, ECR1, CNE9 & SHOX deletion \\
\hline 10 & G1 & Del L10292 - L24245 & CNE-5, -3, -2, SHOX, CNE4, 5, ECR1, CNE9 & SHOX deletion \\
\hline 11 & G1 & Del L05096 - L15055 & CNE4, 5, 9 (Extends to IL3RA) & SHOX enhancer deletion \\
\hline 12 & G1 & Del L10292 - L24245 & CNE-5, -3, -2, SHOX, CNE4, 5, ECR1, CNE9 & SHOX deletion \\
\hline 13 & G1 & Del L20651 - L24247 & SHOX & SHOX deletion \\
\hline 14 & G1 & Del L10292 - L24245 & CNE-5, -3, -2, SHOX, CNE4, 5, ECR1, CNE9 & SHOX deletion \\
\hline 15 & G1 & Del L25087 - L24249 & CNE-5, -3, -2, SHOX, CNE4, 5, ECR1 & SHOX deletion \\
\hline
\end{tabular}

${ }^{\mathrm{a} A l l}$ variants are in heterozygosity.

exon 2, c.243A > T (p.Lys81Asn). This variant is absent from the gnomAD population database (http://gnomad.broadinstitute.org/). It affects a moderately conserved amino acid in the N-terminal of SHOX, but the pathogenicity predictors are inconclusive. The variant is present in a mother and her children, a boy and a girl with LWD. According to the American College of Medical Genetics and Genomics variant classification, this variant has been classified as a variant of unknown significance.

We also performed genetic testing of the recently described SHOX modifier, CYP26C1, ${ }^{25}$ in all children and adults, but no variant of interest was detected.

\section{Anthropometric Characteristics}

Mean birth weights and lengths were $2.950 \pm 360$ and $3.040 \pm 570 \mathrm{~g}$, and $47.7 \pm 1.75$ and $46.3 \pm 1.92 \mathrm{~cm}$ for boys and girls, respectively, lower than Argentinean reference data $(p<0.001){ }^{12}$
The summary of the anthropometric data taken at the patient's first appointment for both children and adults is shown in - Table 3. The median age of children at the first appointment was 4.46 years (range: $0.14-12.07$ years) with a median follow-up of 6.67 years (range: 3.13-19.07). All children and adults had arm spans shorter than -2 SDS for age and sex and extremities:trunk ratio $<-1$ SDS (- Table 3 ).

The height and $\mathrm{SH} / \mathrm{H}$ growth curves for boys and girls are shown in -Figs. 1 and 2. - Fig. $\mathbf{1 A}$ and $\mathbf{B}$ show that 5 boys and 2 girls had growth within normal range while all other children were below percentile 3. Mean SDS heights + SD at their last prepubertal appointment were $-2.03 \pm 1.14$ and $-2.08+0.81$ for boys and girls, respectively. Growth delay was observed during childhood with a mean delta SDS height prepubertal - SDS birth length of $-0.98 \pm 1.19$. Only 5 of the 19 children had reached adult height, with a mean delta SDS adult height - SDS prepubertal of $-0.45 \pm 0.93$. Mean adult height was $-2.61 \pm 1.52$ SDS. 
Table 3 Clinical and anthropometrics characteristics at first appointment in the pediatric $(n=19)$ and adult $(n=11)$ cohorts with SHOX deficiency

\begin{tabular}{|l|l|l|l|}
\hline Children & Total $(\boldsymbol{n}=\mathbf{1 9})$, mean \pm SD & Boys $(\boldsymbol{n}=1 \mathbf{0})$, mean \pm SD & Girls $(\boldsymbol{n}=\mathbf{9})$, mean \pm SD \\
\hline Age, $y$ & $4.46 \pm 3.41$ & $4.46 \pm 2.97$ & $4.48 \pm 3.99$ \\
\hline Birth length SDS & $-1.45 \pm 0.97$ & $-1.29 \pm 0.96$ & $-1.65 \pm 1.06$ \\
\hline Height SDS & $-2.16 \pm 1.34$ & $-2.35 \pm 1.34$ & $-1.97 \pm 1.42$ \\
\hline Arm span SDS & $-3.67 \pm 0.86$ & $-3.48 \pm 0.92$ & $-3.83 \pm 0.83$ \\
\hline SH/H SDS & $4.32 \pm 3.25$ & $4.63 \pm 4.30$ & $4.02 \pm 1.98$ \\
\hline $\begin{array}{l}\text { Extremities-trunk ratio }{ }^{a} \\
\text { below }-1 \text { SDS }\end{array}$ & $19 / 19(100 \%)$ & $10 / 10(100 \%)$ & $9 / 9(100 \%)$ \\
\hline HC/H ratio SDS & $1.53 \pm 0.89$ & $1.05 \pm 1.31(n=9)$ & $1.76 \pm 0.82$ \\
\hline Total hand length SDS & $-1.33 \pm 0.77$ & $-1.17 \pm 0.94$ & $-1.50 \pm 0.57$ \\
\hline BMI SDS (range) & 0.94 & $+1.12(-0.57 /+2.95)$ & $+0.75(-0.63 /+1.87)$ \\
\hline X-ray: Radius length SDS & $-3.65 \pm 1.77$ & $-3.91 \pm 2.38(n=10)$ & $-3.36 \pm 0.71(n=8)$ \\
\hline Adults & Total $(n=11)$ & Male $(n=2)$ & Female $(n=9)$ \\
\hline Height SDS & $-2.70 \pm 1.29$ & $-1.68 \pm 0.98$ & $-2.93 \pm 1.28$ \\
\hline Arm Span SDS & $-4.15 \pm 1.07$ & $-3.65 \pm 0.30$ & $-4.27 \pm 1.16$ \\
\hline SH/H SDS & $3.98 \pm 0.98$ & $4.57 \pm 1.50$ & $3.83 \pm 0.90$ \\
\hline $\begin{array}{l}\text { Extremities-trunk ratio }{ }^{a} \\
\text { below }-1 \text { SD }\end{array}$ & $13 / 13(100 \%)$ & $2 / 2(100 \%)$ & $9 / 9(100 \%)$ \\
\hline HC/H SDS & $2.24 \pm 1.1$ & 1.57 & $2.34 \pm 1.15$ \\
\hline Total hand length SDS & -2.21 SD $=1.09$ & $-0.96(n=1)$ & -2.39 SD $=1.04$ \\
\hline X-ray: Radius length SDS & $-4.83 \mathrm{SD}=1.24(n=8)$ & $-3.67(n=1)$ & $-5.00 \mathrm{SD}=1.24(n=7)$ \\
\hline
\end{tabular}

Abbreviations: BMI, body mass index; HC/H, head circumference/height; SD, standard deviation; SDS, standard deviation score; SH/H, sitting height/height. ${ }^{a}$ Binder G, Ranke MB, Martin DD. Auxology is a valuable instrument for the clinical diagnosis of SHOX haploinsufficiency in school-age children with unexplained short stature. J Clin Endocrinol Metab 2003;88(10):4891-4896.

Eight of nine women and one of the two adult male firstdegree relatives had short stature (plotted at 18 years of age).

-Fig. 2A and B show that disproportionate growth, an $\mathrm{SH} /$ $\mathrm{H}$ ratio of above 2 SDS, was detected by the age of 8 years in 18/19 children compared with Argentinean references according to age and sex. Some children presented with body disproportion as early as 2 years old. Median (range) $\mathrm{SH} / \mathrm{H}$ SDS ratios were $4.53(0.74 / 14.18)$ and $5.24(1.7 / 18.63)$ for the first and last appointments $(p=0.30)$.

Mean prepubertal SH/H SDS ratios were $5.92 \pm 4.14$ and $4.89 \pm 1.34$ for boys and girls, respectively.

$\mathrm{The} \mathrm{SH} / \mathrm{H}$ of first-degree relatives (adults) were plotted at age 17 and all were disproportionate.

The $\mathrm{HC} / \mathrm{H}$ curves are shown in - Fig. 3. Although a total of three males and five females had relative macrocephaly, that is, a $\mathrm{HC} / \mathrm{H}$ ratio greater than $+2 \mathrm{SDS}$, no real macrocephaly (head circumference for age greater than +2 SDS) was observed in children or adults.

$X$-rays: All children had a radius length below -1.9 SDS for age and sex at first appointment at as early as 45 days old (-Table 3 and -Fig. 4). At mean age of 4.46 years, 4/18 children had lucency of the distal ulnar border of the radius and 5/18 triangularization of the distal radial epiphysis and pyramidalization of the distal carpal row. At the last appointment, at mean age of 10.67 years, $8 / 18$ children had lucency of the distal ulnar border of the radius, 10/18 triangulariza- tion of the distal radial epiphysis, and 9/18 pyramidalization of the distal carpal row.

In first-degree relative adults ( $n=10), 100 \%$ had a bowing of the distal end of the radius and $70 \%$ had triangularization of the distal radial epiphysis. All adults had a radius length below -2.0 SDS. X-ray assessment was not possible in one adult because he had previously undergone wrist surgery.

-Fig. 4 shows X-rays of the forearms, a highly variable radiological sign we observed within and between families.

\section{Discussion}

We performed a detailed longitudinal evaluation of the anthropometric data in 19 Argentinean children with molecularly confirmed SHOX alterations and cross-sectional study of 11 of their first-degree relatives with comparisons to Argentine growth references. There are many reports with anthropometric data of patients with SHOX haploinsufficiency, but very few do so longitudinally, and they do not compare measurements with local references. Variations in height, arm span, and changes in body proportions evaluated by $\mathrm{SH} / \mathrm{H}$ ratio were observed.

Children with SHOX haploinsufficiency were born shorter ( -1.45 SDS $)$ than the Argentinean references, suffering growth retardation during childhood with a mean prepubertal height of -2.05 SDS, similar to that described by others. ${ }^{5,7,11}$ 


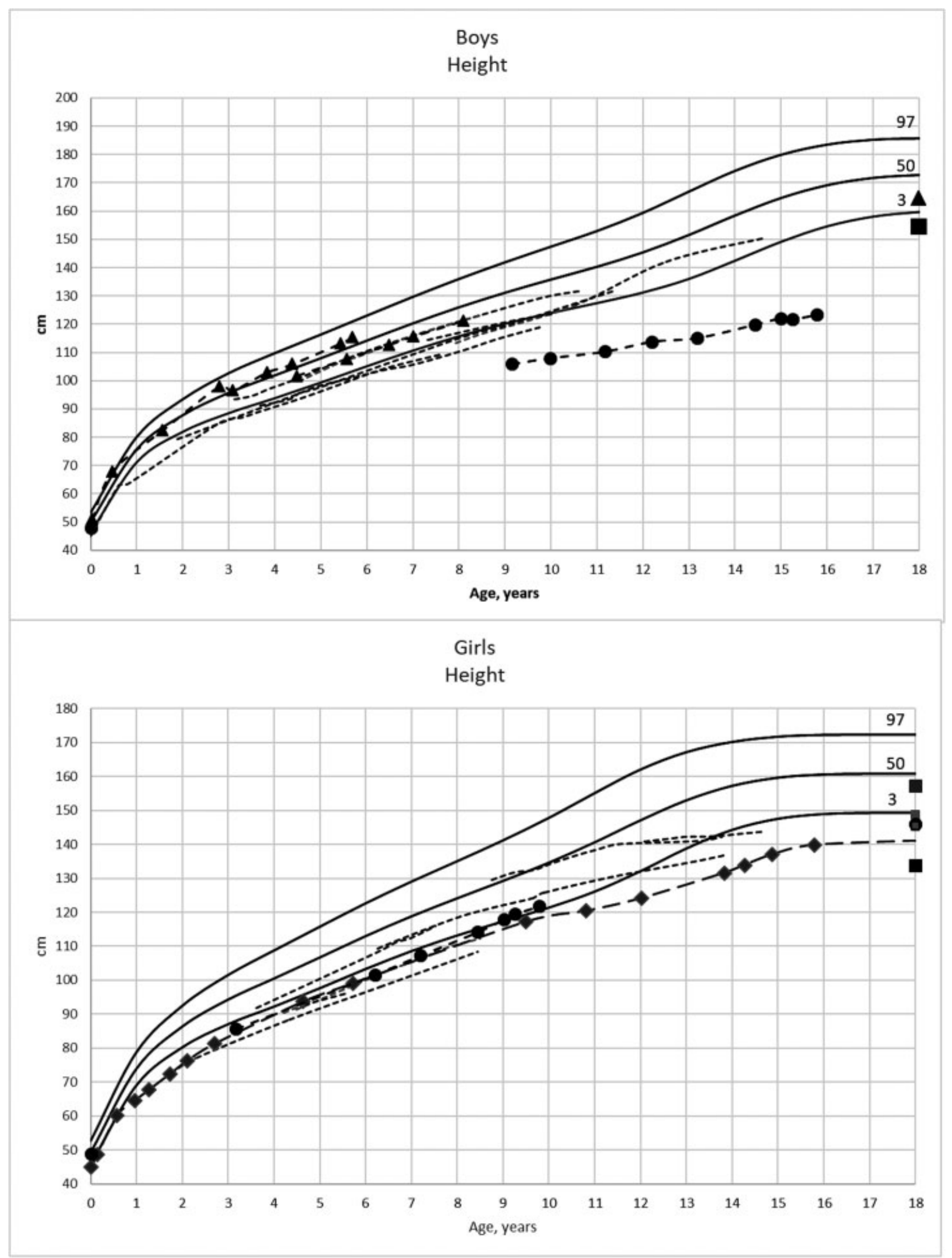

Fig. 1 Height growth curves for all boys and male adults (A) and girls and female adults (B). Members of the family with a previously undescribed missense variant in exon 2, c.243A > T (p. Lys81Asn). The height of the mother was at -2.41 standard deviation score (SDS) and for the girl was at -1.70 SDS, at 9.79 years. The boy had severe growth retardation with a height deficit of -4.43 SDS at 9.15 years and -5.76 SDS at 15.77 years for Argentine references. Members of the family with deletion only in the four downstream regulatory regions of the pseudoautosomal region 1 . The father and children (two boys) had normal growth in height. Girl from family 5 with SHOX deletion. Birth length $45 \mathrm{~cm}(-2.36 \mathrm{SDS})$. Adult height $141.4 \mathrm{~cm}$ at -3.17 SDS for Argentine references. Circles: Members of the family with a previously undescribed missense variant in exon 2, c.243A > T (p. Lys81Asn). The height of the mother was at -2.41 SDS and for the girl was at -1.70 SDS, at 9.79 years old. The boy had severe growth retardation with a height deficit of -4.43 SDS at 9.15 years old and -5.76 SDS at 15.77 years old for Argentine references.

Triangle: Members of the family with deletion only in the four downstream regulatory regions of the pseudoautosomal region 1 . The father and children (two boys) had normal growth in height.

Squares: Girl from family 5 with SHOX deletion. Birth length $45 \mathrm{~cm}(-2.36 \mathrm{SDS})$. Adult height $141.4 \mathrm{~cm}$ at -3.17 SDS for Argentine references. 


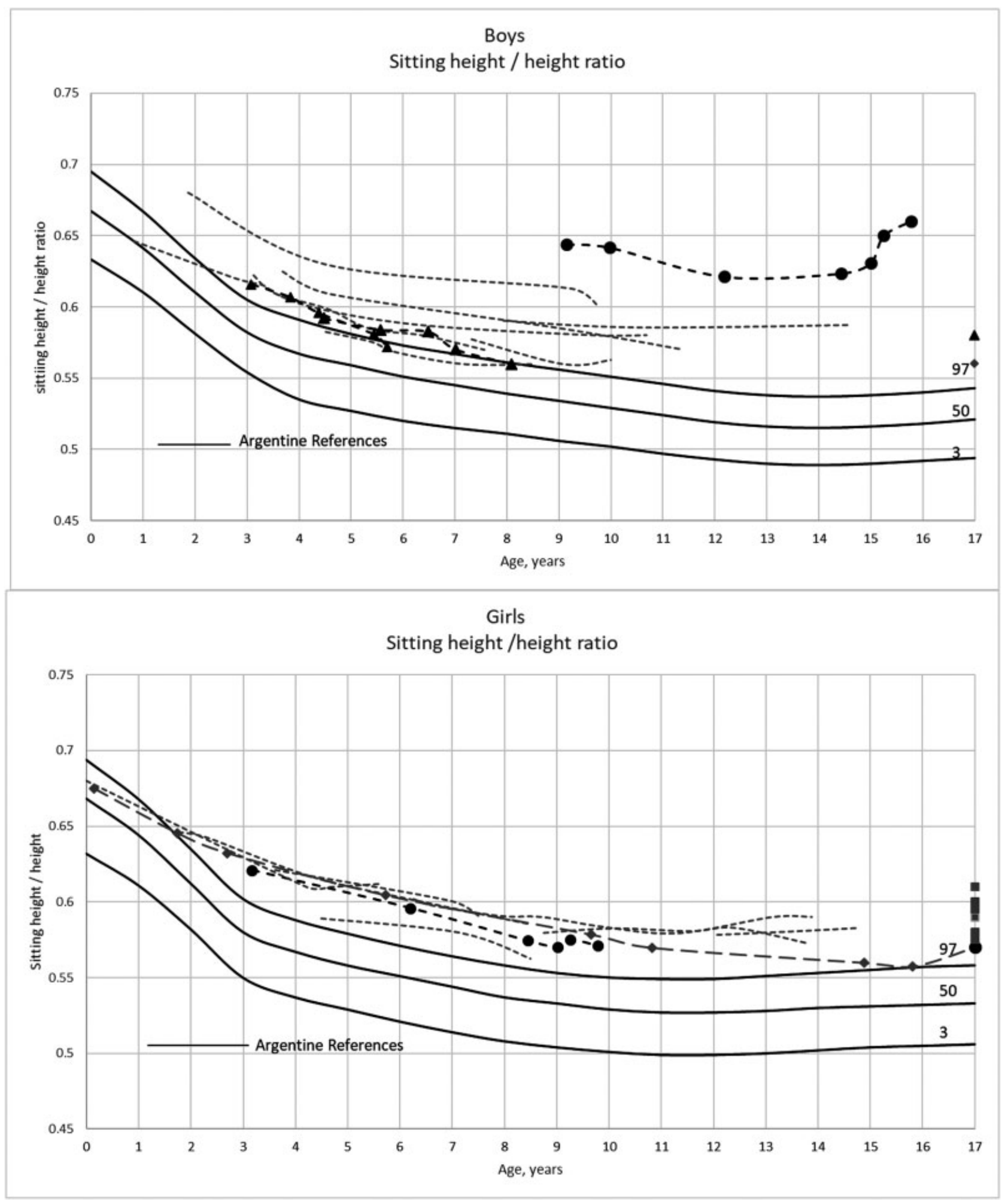

Fig. 2 Sitting height/height growth curves for boys and male adults (A) and girls and female adults (B). Members of the family with a previously undescribed missense variant in exon 2, c.243A > T (p. Lys81Asn). The adult sitting height/height ratio of the mother was +2.96 standard deviation score (SDS) and the sitting height/height ratio of the girl at 9.79 years was +4.22 SDS. The boy had severe body disproportion with a sitting height/height ratio of +14.19 SDS at 9.15 years and +18.63 SDS at 15.77 years for Argentine references. Circles: Members of the family with deletion only in the four downstream regulatory regions of the pseudoautosomal region 1 . The father and children (two boys) had body disproportion. The sitting height/height ratio of the father was +3.51 SDS. The sitting/height ratio were +2.23 SDS and +2.21 SDS at 7.01 and 5.43 years for the two boys, respectively. Squares: Girl from family 5 with SHOX deletion. At first appointment, 45 days old, her sitting height/ height ratio was $0.67,+0.41$ SDS. Adult sitting height/height ratio $0.57,+2.79$ SDS for Argentine references. 

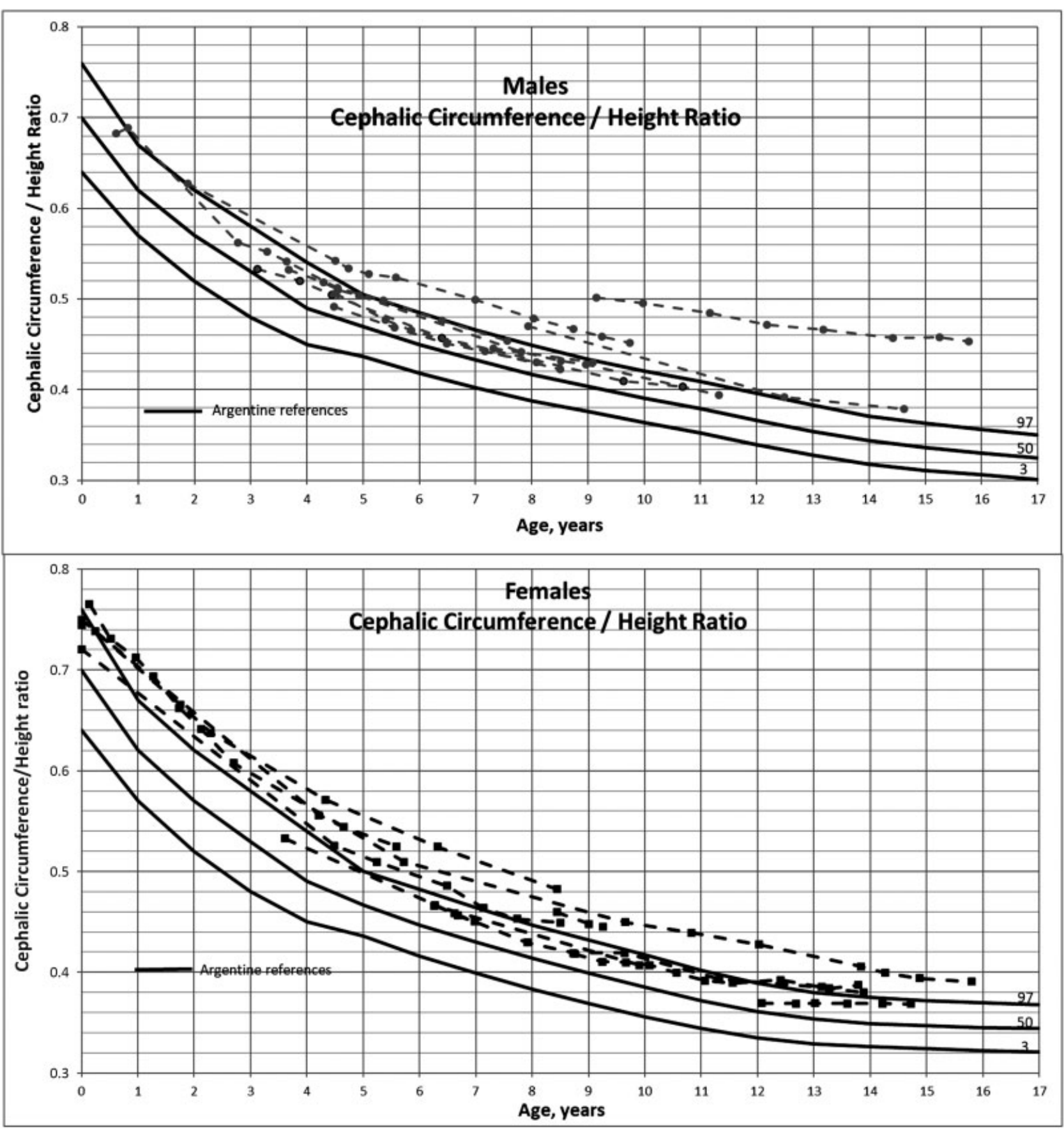

Fig. 3 Growth curves of the head circumference/height ratio in the pediatric cohort: boys (A) and girls (B). Although a total of three males and five females had relative macrocephaly, that is, a head circumference/height ratio greater than +2 standard deviation score (SDS), no real macrocephaly (head circumference for age greater than 2 SDS) was observed in children or adults. Circle: Girls with SHOX deficiency; squares: Boys with SHOX deficiency.

Insufficient data were available to analyze the effect of puberty on the growth of group 1 , but height was even shorter after puberty in the five children who reached adult height, with a mean of -2.6 SDS, indicating a stunted pubertal spurt. These results agree with those observed by Binder et al and Fukami et al. ${ }^{11,26}$

In first-degree relatives of the children, short stature was present in 9/11 adults and females were more affected than males with a similar deficit to that previously reported.

The longitudinal follow-up of body proportions of children compared with local references revealed an $\mathrm{SH} / \mathrm{H}$ ratio of above +2 SDS, an indicator of disproportionately short legs, which was already present as early as 2 years old and persisted during follow-up. Body disproportion, assessed as $\mathrm{SH} / \mathrm{H}$ ratio, in adults was similar, at approximately $+4 \mathrm{SDS}$. Previous reports described an $\mathrm{SH} / \mathrm{H}$ ratio above +2 SDS in children older than age of 6 years. ${ }^{5,7}$ Body proportion changes with age and is different in different populations, ${ }^{27,28}$ so disproportion may be detected before school age if compared with local references for age and sex. ${ }^{14}$

Arm span was reduced for age in all children and adults. We compared our data with Turkish references. ${ }^{13}$ The Turkish 


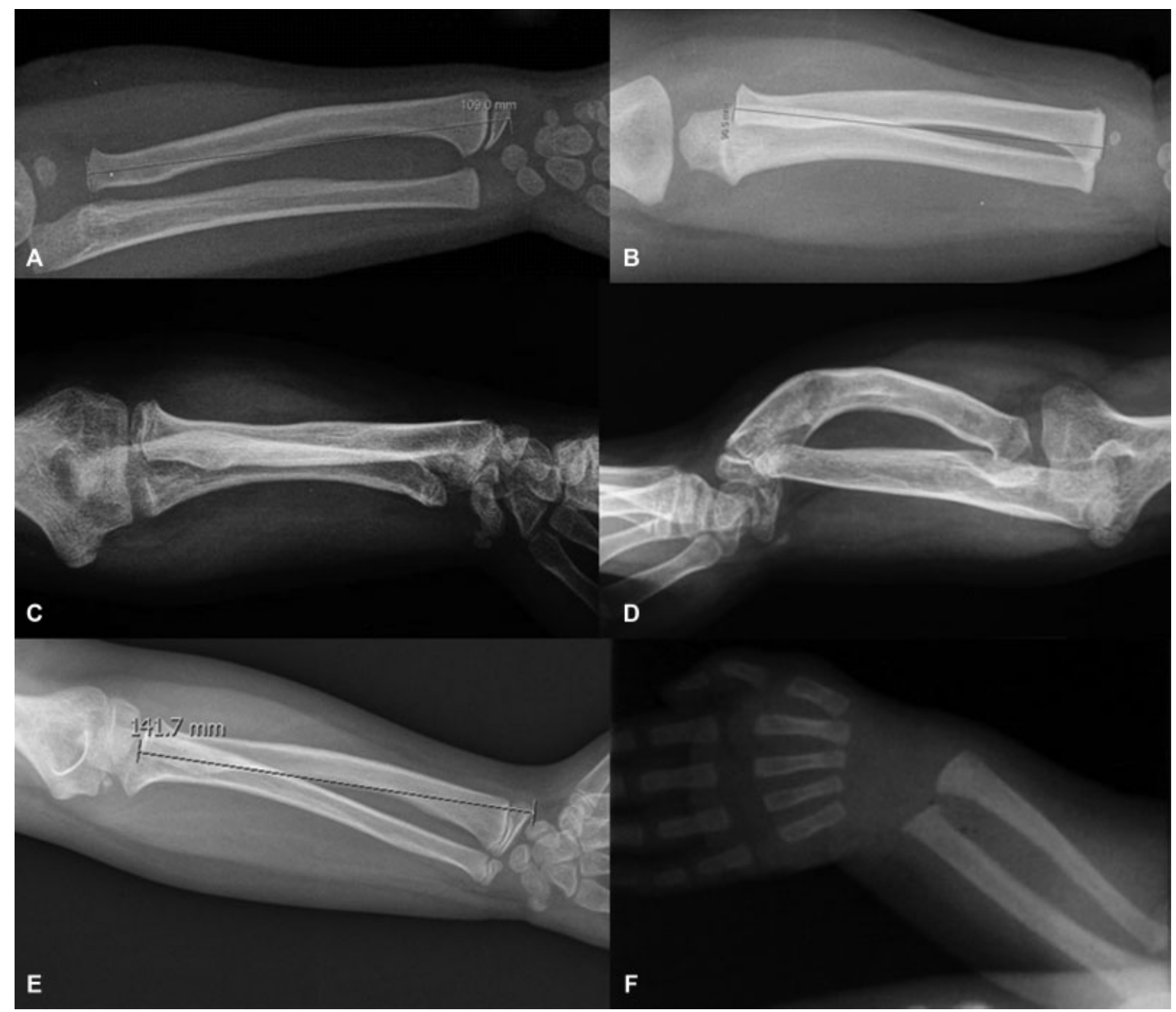

Fig. 4 X-ray of the forearm: Boys (A) and (B) from family with deletion only in the four downstream regulatory regions of the pseudoautosomal region 1. Boy $(A)$ at 4.47 of years, the $X$-ray radius length was $109.0 \mathrm{~mm}$ (-3.43 standard deviation score [SDS]). Boy (B), at 1.83 years, the $X$-ray radius length was $90.4 \mathrm{~mm}(-1.93 \mathrm{SDS})$. Boy (C) and girl (D) from family with undescribed missense variant in exon 2, c.243A > T (p. Lys81Asn). Boy (C), at 12.19 of years had severely compromised radius and ulna more pronounced at the right side. Girl (D), at 8.56 years $X$-ray radius length was $141 \mathrm{~mm}$ (-2.65 SDS). Girl (E), from family 5, with SHOX deletion. At 45 days old, X-ray radius length was $48 \mathrm{~mm}(-2.6$ SDS). Boy (C) at 12.19 years old, severe compromised of radius and ulna, more pronounced at the right side.

populations have a mean limb length shorter than that of the Argentinean population, thus it is likely that the SDS of the arm span in our patients would be more compromised if the data were analyzed with local references. ${ }^{13,14}$

Hand length was slightly reduced in a few patients, but the majority was normal, as expected. Thus, normal hand length is an important clinical sign to help in the differentiation of SHOX deficiency disorders from other mild skeletal dysplasias due to mutations in NPR2, ACAN, NPPC, or IHH. ${ }^{29-33}$

We also examined the X-rays of the children to assess the presence of Madelung deformity and other suggestive signs of SHOX haploinsufficiency.

Shortening of the radius, with a length below -1.9 SDS for age and sex, was found to be the earliest and most frequent radiological sign. All children demonstrated this feature at the first appointment, being as young as 45 days old.
Binder et al described that during infancy and early childhood, children with LWD may have subtle radiologic signs of Madelung deformity (i.e., lucency of the distal radius), but they are usually asymptomatic, and the physical examination is normal. ${ }^{7}$ In our study, we detected a short radius for age and sex even without the lucency of the distal radius. Normalized measurements of the radius, to calculate SDS for age and sex, have not previously been reported in children with SHOX deficiency. We think this would be a useful tool for selecting children to undergo SHOX molecular studies, especially if they have short stature without a clinically evident mesomelia.

In our study, all members of the family with a deletion only in the four downstream regulatory regions of the PAR1 had a milder phenotype with normal height, milder body disproportion, and short radius for age and sex. On the 
contrary, in the family with a previously undescribed missense variant in exon 2, c.243A > T (p. Lys81Asn), the boy has a severe phenotype with a milder presentation in other affected members of the family.

Highly variable phenotypes were seen even within the same family. No correlation has been established between the severity of phenotype and the underlying SHOX pathogenic variant. ${ }^{8,34-37}$ However, based on reports in the French population, deletions of the downstream enhancer region of SHOX appear to be associated with a milder phenotype. ${ }^{6}$

Variations in the clinical phenotype observed between individuals may be due to different genetic background. To date, only one SHOX modifier has been discovered, CYP26C1. ${ }^{25}$ Individuals with SHOX mutations were reported to have a more severe phenotype, when in association with a CYP26C1 mutation, compared with individuals with a sole SHOX mutation. ${ }^{25}$ However, the incidence was very low. Thus, it was not that unexpected when we did not detect any mutation in this study and therefore this gene cannot explain any of the variations observed in our cohort.

In conclusion, Argentinean children with SHOX deficiency are born shorter and experience a growth delay during childhood as well as a stunted pubertal growth spurt.

Body disproportion, evaluated by $\mathrm{SH} / \mathrm{H}$ ratio, an indicator of short legs, was already present in some children as early as 2 years.

Shortening of the radius, with a length below-1.9 SDS, for age and sex, was found to be the earliest and most frequent radiological sign detected, even as early as 45 days old.

We found a previously unreported mutation and add the description of this family.

The combination of body disproportion, evaluated with local references, and a shorter radius for age and sex in children without a clinically evident mesomelia with or without short stature may be useful in early detection of children with SHOX deficiency.

Funding

This work was supported in part by the following grants: MINECO (SAF2015-66831-R and SAF2017-84646-R).

\section{Conflict of Interest}

None declared.

Acknowledgments

We would like to thank the patients and their parents.

\section{References}

1 Belin V, Cusin V, Viot G, et al. SHOX mutations in dyschondrosteosis (Leri-Weill syndrome). Nat Genet 1998;19(01):67-69

2 Shears DJ, Vassal HJ, Goodman FR, et al. Mutation and deletion of the pseudoautosomal gene SHOX cause Leri-Weill dyschondrosteosis. Nat Genet 1998;19(01):70-73

3 Rappold G, Blum WF, Shavrikova EP, et al. Genotypes and phenotypes in children with short stature: clinical indicators of SHOX haploinsufficiency. J Med Genet 2007;44(05):306-313

4 Marchini A, Ogata T, Rappold GA. A track record on SHOX: from basic research to complex models and therapy. Endocr Rev 2016; 37(04):417-448
5 Malaquias AC, Scalco RC, Fontenele EGP, et al. The sitting height/ height ratio for age in healthy and short individuals and its potential role in selecting short children for SHOX analysis. Horm Res Paediatr 2013;80(06):449-456

6 Rosilio M, Huber-Lequesne C, Sapin H, Carel JC, Blum WF, CormierDaire V. Genotypes and phenotypes of children with SHOX deficiency in France. J Clin Endocrinol Metab 2012;97(07):E1257-E1265

7 Binder G, Ranke MB, Martin DD. Auxology is a valuable instrument for the clinical diagnosis of SHOX haploinsufficiency in school-age children with unexplained short stature. J Clin Endocrinol Metab 2003;88(10):4891-4896

8 Ross JL, Scott C Jr, Marttila P, et al. Phenotypes associated with SHOX deficiency. J Clin Endocrinol Metab 2001;86(12):5674-5680

9 Kosho T, Muroya K, Nagai T, et al. Skeletal features and growth patterns in 14 patients with haploinsufficiency of SHOX: implications for the development of Turner syndrome. J Clin Endocrinol Metab 1999;84(12):4613-4621

10 Garcia Rudaz C, Martínez AS, Heinrich JJ, et al. Growth of Argentinian girls with Turner syndrome. Ann Hum Biol 1995;22 (06):533-544

11 Binder G, Renz A, Martinez A, et al. SHOX haploinsufficiency and Leri-Weill dyschondrosteosis: prevalence and growth failure in relation to mutation, sex, and degree of wrist deformity. J Clin Endocrinol Metab 2004;89(09):4403-4408

12 Lejarraga H, del Pino M, Fano V, Caíno S, Cole TJ. Growth references for weight and height for Argentinian girls and boys from birth to maturity: incorporation of data from the World Health Organisation from birth to 2 years and calculation of new percentiles and LMS values [in Spanish]. Arch Argent Pediatr 2009;107(02):126-133

13 Mazicioglu MM, Hatipoglu N, Ozturk A, Gun I, Ustunbas HB, Kurtoglu S. Age references for the arm span and stature of Turkish children and adolescents. Ann Hum Biol 2009;36(03):308-319

14 Del Pino M, Orden AB, Arenas MA, Fano V. Argentine references for the assessment of body proportions from birth to 17 years of age. Arch Argent Pediatr 2017;115(03):234-240

15 Lejarraga H, Heinrich J. Rodríguez. Normas y técnicas de mediaciones antropométricas. Rev Hosp Nino (Lima) 1975;17:171

16 Saunders CL, Lejarraga H, del Pino M. Assessment of head size adjusted for height: an anthropometric tool for clinical use based on Argentinian data. Ann Hum Biol 2006;33(04):415-423

17 Feingold M, Bossert WH. Normal values for selected physical parameters: an aid to syndrome delineation. Birth Defects Orig Artic Ser 1974;10(13):1-16

18 Tanner JM, ed. Growth at Adolescence. 2nd ed. Oxford/London/ Edinburgh/Melbourne: Blackwell Scientific Publications; 1973

19 Marshall WA, Tanner JM. Variations in the pattern of pubertal changes in boys. Arch Dis Child 1970;45(239):13-23

20 Marshall WA, Tanner JM. Variations in pattern of pubertal changes in girls. Arch Dis Child 1969;44(235):291-303

21 Gindhart PS. Growth standards for the tibia and radius in children aged one month through eighteen years. Am J Phys Anthropol $1973 ; 39(01): 41-48$

22 Cole TJ. Fitting smoothed centile curves to reference data. J R Stat Soc Ser A Stat Soc 1988;151:385

23 Cole TJ, Green PJ. Smoothing reference centile curves: the LMS method and penalized likelihood. Stat Med 1992;11(10):1305-1319

24 Pan H, Cole TJ. LMS growth, a Microsoft Excel add-in to access growth references based on the LMS method; 2012; Version 2.77. Available at: http://www.healthforallchildren.co.uk/. Accessed November 8, 2018

25 Montalbano A, Juergensen L, Roeth R, et al. Retinoic acid catabolizing enzyme CYP26C1 is a genetic modifier in SHOX deficiency. EMBO Mol Med 2016;8(12):1455-1469

26 Fukami M, Nishi Y, Hasegawa Y, et al. Statural growth in 31 Japanese patients with SHOX haploinsufficiency: support for a disadvantageous effect of gonadal estrogens. Endocr J 2004;51(02):197-200

27 Bundak R, Bas F, Furman A, et al. Sitting height and sitting height/ height ratio references for Turkish children. Eur J Pediatr 2014; 173(07):861-869 
28 Fredriks AM, van Buuren S, van Heel WJ, Dijkman-Neerincx RH, Verloove-Vanhorick SP, Wit JM. Nationwide age references for sitting height, leg length, and sitting height/height ratio, and their diagnostic value for disproportionate growth disorders. Arch Dis Child 2005;90(08):807-812

29 Hisado-Oliva A, Garre-Vázquez AI, Santaolalla-Caballero F, et al. Heterozygous NPR2 mutations cause disproportionate short stature, similar to Léri-Weill dyschondrosteosis. J Clin Endocrinol Metab 2015;100(08):E1133-E1142

30 Hisado-Oliva A, Ruzafa-Martin A, Sentchordi L, et al. Mutations in C-natriuretic peptide (NPPC): a novel cause of autosomal dominant short stature. Genet Med 2018;20(01):91-97

31 Gkourogianni A, Andrew M, Tyzinski L, et al. Clinical characterization of patients with autosomal dominant short stature due to aggrecan mutations. J Clin Endocrinol Metab 2017;102(02): 460-469

32 Sentchordi-Montané L, Aza-Carmona M, Benito-Sanz S, et al. Heterozygous aggrecan variants are associated with short stature and brachydactyly: description of 16 probands and a review of the literature. Clin Endocrinol (Oxf) 2018;88(06):820-829
33 Vasques GA, Funari MFA, Ferreira FM, et al. IHH gene mutations causing short stature with nonspecific skeletal abnormalities and response to growth hormone therapy. J Clin Endocrinol Metab 2018;103(02):604-614

34 Schiller S, Spranger S, Schechinger B, et al. Phenotypic variation and genetic heterogeneity in Léri-Weill syndrome. Eur J Hum Genet 2000;8(01):54-62

35 Grigelioniene G, Schoumans J, Neumeyer L, et al. Analysis of short stature homeobox-containing gene (SHOX) and auxological phenotype in dyschondrosteosis and isolated Madelung deformity. Hum Genet 2001;109(05):551-558

36 Benito-Sanz S, Royo JL, Barroso E, et al. Identification of the first recurrent PAR1 deletion in Léri-Weill dyschondrosteosis and idiopathic short stature reveals the presence of a novel SHOX enhancer. J Med Genet 2012;49(07):442-450

37 Bunyan DJ, Baker KR, Harvey JF, Thomas NS. Diagnostic screening identifies a wide range of mutations involving the SHOX gene, including a common $47.5 \mathrm{~kb}$ deletion $160 \mathrm{~kb}$ downstream with a variable phenotypic effect. Am J Med Genet A 2013;161A(06): 1329-1338 